\title{
Impact of Lean Technology on Overall Equipment Effectiveness
}

\author{
${ }^{1}$ Elvira D. Khisamova, ${ }^{2}$ Irina A. Kodolova, ${ }^{3}$ Aliya A. Kucherbaeva \\ ${ }^{1-3}$ Kazan Federal University \\ Email: ela_76@mail.ru
}

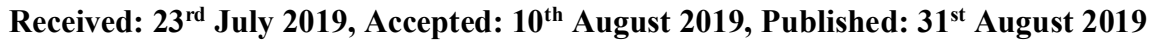

\begin{abstract}
The spatio-temporal production process is considered and the necessity of its organization on the basis of lean technology is justified. The role of the basic tool for organizing a lean production flow - Total Productive Maintenance (TPM) - is noted and the overall equipment effectiveness (OEE) used in continuous production has been calculated. It was found that the system of general maintenance and repair of equipment is a key tool to improve the efficiency of the organization of production processes in continuous sequential production.

From our point of view, the production process is a set of interrelated main, auxiliary and servicing processes of using labor, material and financial resources per unit of time per unit of raw materials, materials, semi-finished products for the purpose of releasing the required quantity of products of the required quality with established using interrelated methods and methods of rational combination of living labor with the means of production, taking into account the minimization of production risks.
\end{abstract}

\section{Keywords}

Manufacturing Process, Lean Manufacturing, Total Productive Maintenance, Overall Equipment Effectiveness, Total Productive Maintenance, Overall Equipment Effectiveness, Down Time Loss, Speed Loss, Quality Loss, Availability, Performance; Quality

\section{Introduction}

Production is a key stage in the product life cycle, and the end results of the enterprise's operation depend critically on how rationally and economically efficient it is organized. It is at the stage of implementation of production processes that technical and economic indicators are laid. Achieving the best values of the indicators provides the company with profit growth, increasing profitability of production, expanding the market for products and improving the competitiveness of the enterprise [5].

In our opinion, it is necessary to consider the production process from the point of view of progressive methods of organizing production, namely lean technologies.

The basic tool for organizing lean production flow is Total Productive Maintenance (TPM) [6]. The main aspects of TPM are: improving the performance and service life of equipment due to better care and attention to the requirements for operation; increasing the productivity and quality of equipment maintenance through training and increasing workers' motivation; collective identification of the causes of malfunctions, search for opportunities to improve performance due to redevelopment of working premises, changes in changeover operations [8].

\section{Methods}

The brick production process was organized in such a way that all stages of brick production follow each other, and any stage of batch processing cannot begin until the previous stage is completed - such an organization follows from the specifics of the production process. Thus, in the enterprise under study, the production process is continuous, that is, the plant operates around the clock in three shifts. Stopping of production occurs only due to unforeseen circumstances, or during scheduled maintenance work. It should be noted that the planned shutdown of the tunnel kiln is performed once a year, due to the time consuming due to its slow cooling and heating to the desired temperature. Since the production is continuous, during the repair and maintenance work of the main tunnel kiln, which lasts 14 days, the production process stops completely, which carries with it the downtime of equipment downtime and economic losses, respectively.

By the nature and scale of the products, the analyzed production process refers to a simple production process, since only one type of product is made - red ceramic bricks through a series of sequential manufacturing operations. Depending on the participation of workers, production refers to automated. Workers-operators monitor the regulatory indicators of the flow of the production process with the help of special sensors installed on computerized equipment.

We represent in the form of a simplified flowchart the process of production of a ceramic brick in the enterprise under study for a more visual representation of it. A block diagram of the main production process is shown in Figure 1 . 


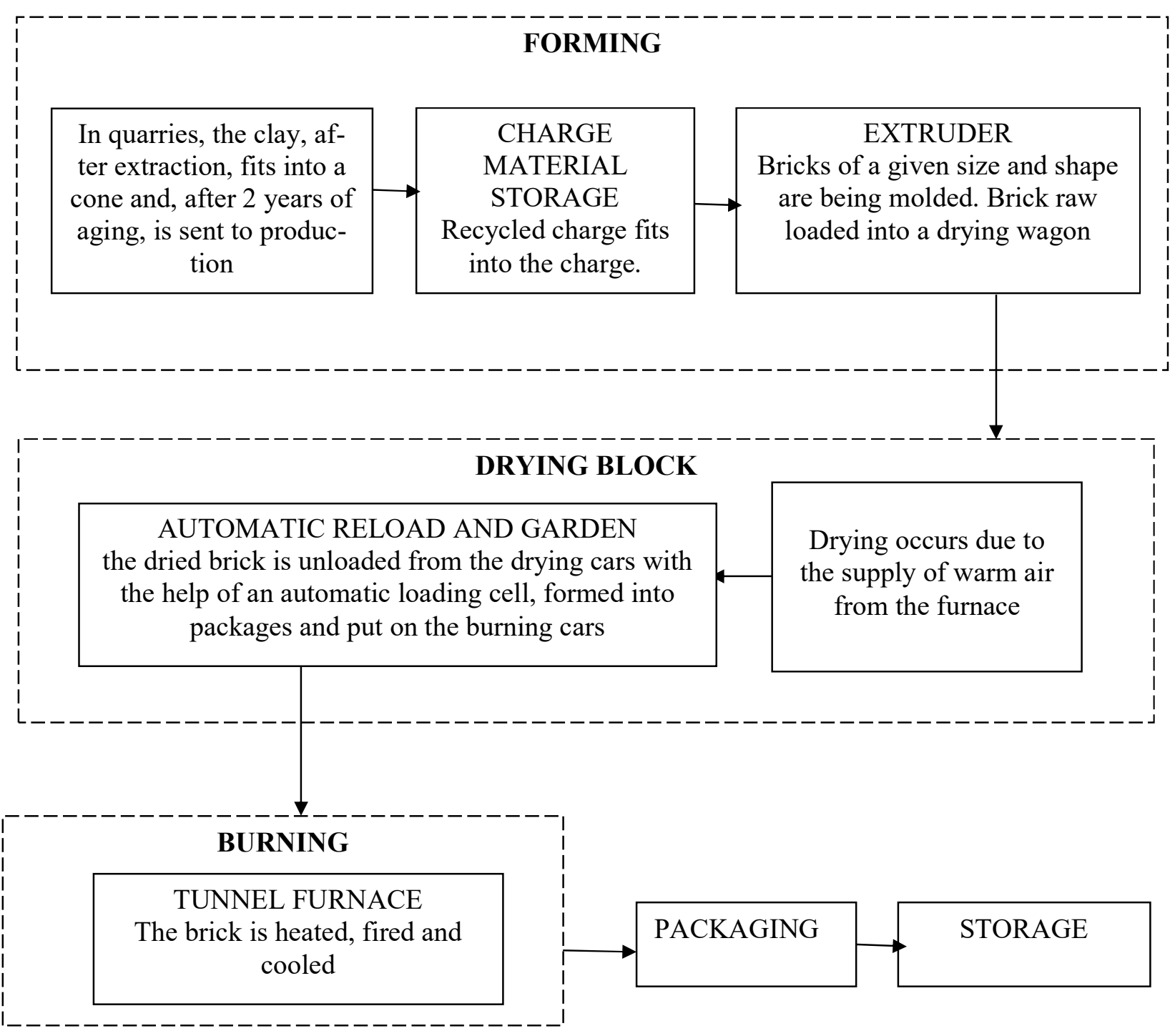

Fig. 1: Production Scheme of Ceramic Bricks

Through transforming actions, the raw materials (clay with various types of impurities) are transformed into finished products - ceramic bricks. It should be noted that no chemical effects on the feedstock, except for temperature, are not produced. The feedstock is recycled after two years of aging in special shrinkable cones from the moment they are mined in quarries.

The brick production process is a continuous sequential production process, as a result of which the initial raw material (clay) goes through processing stages (grinding, dismounting, pressing, molding, drying, burning, cooling, packaging). All the above operations are performed automatically. Then a special loader truck takes the packaged bricks to the finished product warehouse.

In the time aspect, the brick production process takes a total of 8800 minutes.

Thus, the time of one complete production cycle at the studied enterprise is:

$\mathrm{T}=480 \mathrm{~min} .+480 \mathrm{~min} .+1380 \mathrm{~min} .+2280 \mathrm{~min} .+2040 \mathrm{~min} .+2040 \mathrm{~min} .+40 \mathrm{~min} .+60 \mathrm{~min}=8800 \mathrm{~min}$.

The total time of movement of semi-finished products between the stages of the production process is 20 minutes, the waiting time for loading onto the drying cars is 20 minutes. included in the composition of the time stage. Thus, the processing time of products is 8720 minutes.

The TPM concept is aimed at achieving an ideal technical condition of the equipment due to competent maintenance, regular preventive maintenance and systematic elimination of losses. But in order to work to reduce losses associated with the maintenance of equipment, it is necessary to calculate its effectiveness [8].

At the studied enterprise, it is proposed to use the TPM tool, the main tasks of which are: reducing the number and time of emergency downtime; improving the efficiency of planned work processes; eliminating shallow stops and lowering speeds.

The overall equipment performance indicator (OEE) is not based on the nominal capacity of the equipment and its operating time, but evaluates the effectiveness from three sides: accessibility (takes into account losses at stops); performance (takes into account the loss in speed); quality (takes into account losses in quality (waste, scrap)) [8]. 
Thus, the implementation of the stages of the system TPM will eliminate three main categories of losses: Down Time Loss (DTL); loss in speed (SL); loss in quality (QL).

With the help of the OEE (Overall Equipment Effectiveness) indicator, it is possible to estimate the overall efficiency of the equipment and analyze the loss of time in order to reduce or eliminate them. The calculation of OEE is based on the measurement of specific performance indicators characterizing the availability (A) of equipment for work; performance $(\mathrm{P})$ equipment; quality $(\mathrm{O})$ of products manufactured on equipment.

\section{Results}

As the collected data showed, the cause of downtime is most often the failure of equipment at the first stage of production. The annual design capacity of the line is $\operatorname{Pr}=22.5$ million pcs. in year.

To determine the hourly performance of the equipment, we take: the number of days of equipment operation in a year is 349.16 days a year is a planned shutdown of equipment for the purpose of maintenance. Hourly productivity of finished products is calculated by the formula 1 :

$$
P_{h}^{s}=\frac{P_{g}^{m} \cdot 100}{349 \cdot 24} \mathrm{~kg} / \mathrm{h},
$$

where 24 is the number of hours per day;

$$
P_{h}^{s}=\frac{22500 \cdot 10^{3} \cdot 100}{349 \cdot 24 \cdot(100-2)}=2686 \mathrm{pcs} / \mathrm{h}
$$

Thus, the technological line operates at a nominal speed of 2686 pcs. at one o'clock. Actual performance varies, rarely reaching nominal rates. In one shift, the equipment produces a batch of finished products - red ceramic bricks. The nominal batch size is 21490 pcs.

Calculate the performance of the equipment in minutes, in order to estimate the loss from equipment downtime, using the formula 2 .

$$
P_{h}^{s}=\frac{P_{g}^{m} \cdot 100}{349 \cdot 24 \cdot 60} \mathrm{~kg} / \mathrm{h},
$$

where 24 is the number of hours per day;

60 - the number of minutes in one hour.

$$
P_{h}^{s}=\frac{22500 \cdot 10^{3} \cdot 100}{349 \cdot 24 \cdot 60}=44,8 \mathrm{pcs} / \mathrm{min}
$$

To assess the overall efficiency of the equipment, data on line downtime, the number of defective products from the lot, as well as the number of bricks produced per lot were collected in shifts within 15 days. The results of the formation of empirical information for the study are presented in table 1 .

\begin{tabular}{|l|l|l|l|l|l|l|l|l|l|}
\hline \multirow{2}{*}{ Day } & \multicolumn{3}{l}{ Change 1} & \multicolumn{2}{l}{ Change 2 } & \multicolumn{2}{l|}{ Change 3 } \\
\cline { 2 - 10 } & $\begin{array}{l}\text { Plain, } \\
\text { min }\end{array}$ & $\begin{array}{l}\text { Losses, } \\
\text { pc }\end{array}$ & $\begin{array}{l}\text { Amount, } \\
\text { pc }\end{array}$ & $\begin{array}{l}\text { Plain, } \\
\text { min }\end{array}$ & $\begin{array}{l}\text { Losses, } \\
\text { pc }\end{array}$ & $\begin{array}{l}\text { Amount, } \\
\text { pc }\end{array}$ & $\begin{array}{l}\text { Plain, } \\
\text { min }\end{array}$ & $\begin{array}{l}\text { Losses, } \\
\text { pc }\end{array}$ & $\begin{array}{l}\text { Amount, } \\
\text { pc }\end{array}$ \\
\hline 1 & 0 & 355 & 20382 & 90 & 493 & 20490 & 0 & 381 & 20992 \\
\hline 2 & 0 & 367 & 20343 & 1 & 439 & 20160 & 241 & 508 & 20490 \\
\hline 3 & 186 & 351 & 20490 & 0 & 343 & 20191 & 0 & 481 & 20382 \\
\hline 4 & 0 & 340 & 20238 & 89 & 462 & 20470 & 0 & 415 & 20136 \\
\hline 5 & 0 & 471 & 20372 & 0 & 367 & 20085 & 62 & 365 & 20286 \\
\hline 6 & 204 & 365 & 20428 & 0 & 398 & 20490 & 0 & 484 & 20297 \\
\hline 7 & 59 & 334 & 20490 & 311 & 539 & 20359 & 0 & 320 & 20490 \\
\hline 8 & 68 & 441 & 20490 & 44 & 341 & 20408 & 385 & 521 & 20386 \\
\hline 9 & 0 & 369 & 20143 & 0 & 490 & 20377 & 53 & 367 & 20483 \\
\hline 10 & 59 & 417 & 20490 & 0 & 351 & 20002 & 0 & 433 & 20188 \\
\hline 11 & 0 & 497 & 20334 & 0 & 509 & 20490 & 0 & 403 & 20011 \\
\hline 12 & 1 & 359 & 19945 & 0 & 437 & 20221 & 0 & 333 & 20490 \\
\hline 13 & 211 & 509 & 20318 & 0 & 469 & 20416 & 0 & 500 & 20389 \\
\hline 14 & 0 & 389 & 20438 & 0 & 501 & 20478 & 405 & 325 & 20490 \\
\hline 15 & 80 & 429 & 20490 & 91 & 539 & 20490 & 0 & 352 & 20480 \\
\hline
\end{tabular}

Table 1: Shift Idle Time and Reject Volume for 15 Business Days of the Month

Consider the data in table 1 for a specific example. Day 10, change 1, batch size 20490 pcs., Maximum productivity - 44.8 pcs. per minute, therefore, the estimated processing time of the batch of raw materials is 457 minutes. But there was a loss of time - 19 minutes. Consequently, the real time of processing a batch of raw materials was 476 minutes, which means that the real equipment productivity on the tenth day was $20490 \mathrm{pcs} . / 476 \mathrm{~min}=43 \mathrm{pcs} / \mathrm{min}$ 
The collected data made it possible to calculate the overall efficiency of the equipment and identify weaknesses in the production process. Based on the data from the tables, it is possible to calculate the downtime and line operation time and determine the availability of equipment.

The summarized data on equipment downtime and reject volume for three shifts are presented in table 2.

\begin{tabular}{|l|l|l|l|l|}
\hline Day & $\begin{array}{l}\text { Plain, } \\
\text { min }\end{array}$ & $\begin{array}{l}\text { Losses, } \\
\text { pc }\end{array}$ & $\begin{array}{l}\text { Amount, } \\
\text { pc }\end{array}$ & $\begin{array}{l}\text { Production, } \\
\text { pcs }\end{array}$ \\
\hline 1 & 90 & 1229 & 61864 & 60635 \\
\hline 2 & 242 & 1314 & 60993 & 59679 \\
\hline 3 & 186 & 1175 & 61063 & 59888 \\
\hline 4 & 89 & 1217 & 60844 & 59627 \\
\hline 5 & 62 & 1203 & 60743 & 59540 \\
\hline 6 & 204 & 1247 & 61215 & 59968 \\
\hline 7 & 370 & 1193 & 61339 & 60146 \\
\hline 8 & 497 & 1303 & 61284 & 59981 \\
\hline 9 & 53 & 1226 & 61003 & 59777 \\
\hline 10 & 59 & 1201 & 60680 & 59479 \\
\hline 11 & 0 & 1409 & 60835 & 59426 \\
\hline 12 & 1 & 1129 & 60656 & 59527 \\
\hline 13 & 211 & 1478 & 61123 & 59645 \\
\hline 14 & 405 & 1215 & 61406 & 60191 \\
\hline 15 & 171 & 1320 & 61460 & 60140 \\
\hline Total & 2640 & 18859 & 916508 & 897649 \\
\hline
\end{tabular}

Table 2: Total Downtime and Rejects for 15 Business Days of the Month

The study was conducted within 15 working months. Given that the production process is continuous, the planned production time of the equipment for 15 days is 360 hours or 21600 minutes. Total downtime is 2640 minutes. The production time of the entire batch of products for 15 days is:

961108 pcs. $/ 44.8$ pcs. $\min =21453.3 \mathrm{~min}$.

$\mathrm{OT}=\mathrm{PPT}-\mathrm{DTL}=21600 \mathrm{~min} .-2640 \mathrm{~min} .=18960 \mathrm{~min}$.

$\mathrm{A}=\mathrm{OT} / \mathrm{PPT}=18960 \mathrm{~min} . / 21600 \mathrm{~min} .=0,8778$ or $87.78 \%$.

Equipment performance $\mathrm{P}$ allows you to estimate the loss of equipment speed. So the equipment performance indicator is calculated as the ratio of the ideal cycle time for the production of a given volume of products to the real time.

$\mathrm{P}=897649 / 44.8 /(21600+2640)=0.8266$ or $82.66 \%$.

We calculate the quality indicator $\mathrm{Q}$ of the products produced on the equipment, which allows you to analyze the loss in quality:

$\mathrm{Q}=897649 / 916508=0.9794$ or $97.94 \%$.

Thus, the overall effectiveness of OEE equipment in 15 working days per month is:

$\mathrm{OEE}=0.8778 \times 0.8266 \times 0.9794=0.711$ or $71.1 \%$.

For the studied production, there are reserves for increasing the efficiency of equipment use by approximately $14 \%$ to the preferred $85 \%$. It should be noted that the OEE indicator is static in nature and gives an estimate of the overall efficiency of the use of equipment for a selected period of time. However, if the analyst does not have reliable data for the entire time of the equipment operation about its availability, performance and product quality, then it is not possible to estimate the effectiveness of the equipment for the total equipment operation time from the time of installation and launch. If we take the average values of the three components constituting the OEE, then this indicator will have a serious error in the calculations, since by averaging possible fluctuations in the availability and performance of equipment, as well as product quality, are smoothed.

We have proposed an indicator of the share of emergency works in relation to the planned repair and technical works Dav.rab (formula 3).

Dav.rab. $=\mathrm{AR} / \mathrm{PRx} 100 \%$,

where AR - time of emergency work;

PR - the time of the planned work on repair and maintenance.

We will calculate the ratio of emergency work to scheduled, based on 2018 data. Thus, 960 hours or 57600 minutes are planned for 2018 technical service and repair. The availability of equipment for the study period (15 days) is $87.77 \%$. Find the number of scheduled maintenance works for 15 days:

$57600 / 12$ months $/ 2=2400 \mathrm{~min}$.

Thus, 2400 min. scheduled work accounts for 15 days. Based on the data in table 2, the amount of equipment downtime during the study period was 2640 minutes. Find the ratio of emergency and planned repair work according to the formula 3:

Dav.rab. $=\mathrm{AR} / \mathrm{PR}=2640 / 2400 \times 100 \%=110 \%$ 
Taking into account the fact that the time of the planned work is constant, then the David.rab indicator. tend to zero while reducing the time of emergency operations. However, by reducing emergency work, the overall availability of equipment increases.

Thus, the company must strive for a situation where the schedule of availability of equipment will be higher than the schedule of the ratio of emergency and planned work.

To achieve the planned indicators, it is planned to solve the problem of improving the efficiency of the planned work processes, reducing the number and time of emergency downtime through the use of TRM tools, eliminating the problems of small stops and reducing the equipment speed.

\section{Findings}

Thus, on the basis of a system of indicators of a lean production flow, it is possible to assess the degree of efficiency of the organization of the enterprise's production processes. It is necessary to pay attention to the fact that in continuous production with automated equipment the main factor of control and optimization is the availability of equipment, its performance and reliability, as well as the level of product quality. By using the tool TPM solve these problems. Based on the results of a study of the organization of a lean production flow, it can be concluded that the equipment at the enterprise is not used efficiently enough, which confirms the OEE figure of $71 \%$. The decrease in this indicator was primarily affected by equipment downtime as a result of breakdowns, stops for maintenance and repairs. The level of marriage in the enterprise is on average $2 \%$, which is the norm and meets the average industry indicators. Thus, the enterprise under study is proposed to introduce an indicator to assess the effectiveness of planned equipment shutdowns for technical repairs and maintenance.

Thus, the task of optimizing the program of preventive maintenance of equipment, as well as reducing the time of emergency operations is relevant for the enterprise under study.

Optimization of the maintenance program was carried out in order to: increase equipment reliability; reducing the number of unplanned downtime; reducing the time of emergency work; reduce labor costs for the maintenance of equipment. These measures would be impossible to implement without reliable and complete data on the equipment, work performed, defects arising. At the same time, data sources are located directly at the equipment, and a group of analysis and decision-making was organized at the level of enterprise management with the involvement of employees directly performing work on the equipment.

\section{Conclusion}

In the course of studying the organization of the production process at the enterprise under investigation, it was established that the process for the production of bricks functions in accordance with modern technologies for the production of ceramic products from clay. The production line is fully automated, which eliminates the influence of the human factor. Manufactured products are checked for compliance with quality standards. However, as shown by the analysis of the results of the enterprise, production has a low profitability, the cost growth rate outpaces the revenue growth rate, which leads to a decrease in the company's marginal profit and adversely affects the main performance indicators. One of the tasks of the enterprise for the near future is to increase the competitiveness of the products manufactured by reducing its cost price while maintaining a given level of quality.

The study found that the system of general maintenance and repair of equipment is a key tool to improve the efficiency of the organization of production processes in continuous sequential production. First, the main types of losses in continuous production are the loss of time due to equipment downtime, while the TPM system is aimed at reducing emergency downtime and increasing the available time of equipment operation. Secondly, the system TPM is not only aimed at reducing equipment breakdowns, by planning preventive work, but also at increasing the efficiency of work on eliminating emergency situations on the production line.

To assess the effectiveness of planned work, the author proposed an indicator of the ratio of emergency and planned work. By tracking the dynamics of this indicator, it is possible to assess the results of the implemented measures to improve the efficiency of emergency operations, as well as the number of equipment breakdowns.

It should be noted that the creation of a plan of preventive work, regulations of periodic maintenance of equipment, maps of daily maintenance of equipment contributes to the standardization of these works, which allows them to perform faster and more efficiently.

\section{Acknowledgements}

The work is performed according to the Russian Government Program of Competitive Growth of Kazan Federal University.

\section{References}

1. Chase Richard B. Production and operational management Chase Richard B., Ek-Vilaine Nicholas J., Jacobs Robert F. - Ed. 8th. - M.: Williams, 2013. - 704 p.

2. Denis P. Hobbs. The introduction of lean manufacturing. practical guide to business optimization / Per. from English - Minsk: Grevtsov Publisher, 2007. - 352 p.

3. Elvira Kh., Fanisovna Aliya N., Arkadevna Irina K., ORGANIZATION OF THE PERFORMANCE PRODUCTION FLOW//AD ALTA-JOURNAL OF INTERDISCIPLINARY RESEARCH. - 2017. - Vol.7, Is.2. - P.145-147. 
4. Jeffrey Liker, Michael Joseus. Corporate culture Toyota: Lessons for other companies / Trans. from English - Alpina Publishers, 2011. - 354 p.

5. Khisamova E. D. Network model of project «Lean Production» // Journal of Physics: Conference Series. 2018. - Vol.1015, Is.4, Art. № 042019.

6. Khisamova E.D, Rafisovich Galiev L, Kodolova I.A., Project quality assurance//Astra Salvensis. - 2017. Vol.2017, Is. - P.603-618.

7. Khisamova Elvira D., Khasanshina Leyla I, Kodolova Irina A., THE CONCEPT OF LEAN MANUFACTURING IN GEOLOGICAL EXPLORATION ACTIVITIES//IIOAB JOURNAL. - 2018. - Vol.9, Is. P.153-156.

8. Khisamova, E.D., Komarov, M.V., Shiriev, R.I., Nizametdinov, Sh.R., Zakirov, A.I. Lean production in the retail network of PJSC TATNEFT: a training manual. - M.: Deepak, 2016. - 144 p.

9. Taiichi O. The production system of Toyota. Departing from mass production -M.: ICSI. - 2005. P. 192.

10. Vomek, James P., Jones, Daniel T. Lean Manufacturing: How to get rid of losses and achieve prosperity of your company / Trans. from English - 5th ed. - M.: Alpina Business Books, 2010.— 473 p. 